From: KININS-II: Biochemistry, Pathophysiology, and Clinical Aspects

Edited by Setsuro Fujii, Hiroshi Moriya, Tomoji Suzuki

(Plenum Pubiishing Corporation, 1979)

HUMAN URINARY KALLIKREIN - BIOCHEMICAL AND PHYSIOLOGICAL ASPECTS

R. Geiger, U. Stuckstedte, B. Förg-Brey and E. Fink

Abteilung fur Klinische Chemie und Klinische Biochemie

in der Chirurgischen Klinik der Universität München

Nussbaumstrasse 20, D-8000 München 2, Germany

The history of kallikrein begins with the discovery of urinary kallikrein more than fifty years ago. The renal origin of urinary kallikrein, though not finally proved, is largely accepted. A possible role of kallikrein in the regulation of kidney function and blood pressure has been debated for a long time (Pisano and Auster, 1976). However, neither the question for its origin, nor for its physiological role is finally settled.

\title{
Isolation and Characterization
}

As a first step in the development of a radioimmunoassay and of enzymatic assays for human urinary kallikrein an isolation method for the enzyme was set up (Geiger et al. 1977). The method is summarized in Table 1 (a slightly different method was reported earlier, Mann and Geiger, 1977).

Preparations of human urinary kallikrein obtained from different urine pools were subjected to polyacrylamide gel electrophoresis at $\mathrm{pH} 6$ and 8 . Two different patterns of protein bands were obtained. For some preparations only one band was visible after staining, whereas other preparations were resolved into three bands as described also by Matsuda et a1. (1976). All bands contained active kallikrein as was demonstrated by active enzyme staining using Z-Ser-Pro-Phe-Arg-MNA and coupling with Fast Blue B Salt (Smith et al. 1975). After incubation with Trasylol, however, only a single band of lower electrophoretic mobility was detected (Fig. 1) for all preparations. 
Table 1 .

Isolation of human urinary kallikrein

\section{Steps}

Collection of human male urine

Dialysis

Lyophilization

Extraction of the crude urine powder

Sephacryl S-200

Trasylol Sepharose

DEAE-Sepharose
Purification

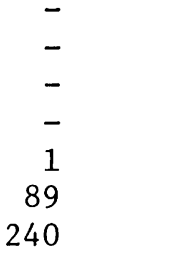

Amino acid analyses of the human urinary kallikrein were done by common methods, carbohydrate content was determined as described by Krystal and Graham (1976). The results are shown in Table 2 and 3 . According to our preliminary results, the amino acid compositions of human urinary kallikrein is very similar to that of pig pancreatic B-kallikrein. The values for Ser, Gly, Ala, Cys and Met are identica1, whereas minor differences exist for the other amino acids. Some differences also exist in the amino acid compositions of preparations isolated from different urine pools.
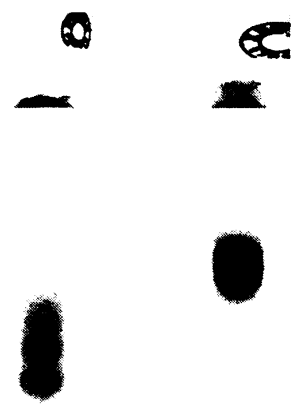

A

B

$$
\cdots
$$

Fig. 1. Acrylamide gel electrophoresis (7.58\% gel, $\mathrm{pH} 8$ ) of human kallikrein.

A: purified enzyme

B : purified enzyme complexed with Trasylol 
Table 2 .

Amino acid composition of kallikreins from human urine and porcine pancreas.

Tryptophan was not determined, cystein after performic acid oxidation (Hirs 1976).

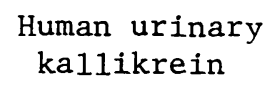

Asp

Thr

Ser

G1u

Pro

G1y

Ala

Cys

Va1

Met

Ile

Leu

Tyr

Phe

Lys

His

Arg

$\operatorname{Trp}$

$20-23$
14
14
$28-30$
14
22
$12-14$
10
$13-16$
4
$8-9$
18
9
$8-12$
$8-12$
$8-9$
6
$?$

$20-23$

$8-30$

14

$2-14$

10

4

$8-9$

18

9

$8-12$

$-9$

?
Porcine pancreatic B-kallikrein (Fiedler et al. 1977)

Table 3 .

Carbohydrate content of human urinary kallikrein and porcine pancreatic kallikrein

$$
\text { Kallikrein from }
$$

Porcine pancreas

form $A$

form $B$.

Human urine
Carbohydrate content $\mathrm{g} / 100 \mathrm{~g}$ protein

28
15
14
23
16
22
13
10
10
4
12
20
7
10
10
8
3
7

28

15

23

16

13

10

0

12

20

10

10

3

7

(Fiedler et al.

1975)

5.6

11.5

$10.5-15.6$ 
The differences in both amino acid composition and electrophoretic patterns suggest that our preparations of human urinary kallikrein contain multiple forms as a result of limited proteolysis. Limited proteolytic attack causes cleavages within a protein chain, eventually resulting in the release of single amino acids or peptides. These cleavages and the loss of parts of the protein molecule can give rise to changes in electrophoretic mobility and amino acid composition. Multiple forms caused by limited proteolysis have also been observed for pig pancreatic kallikrein (Fiedler et al. 1977).

\section{Assay Methods}

It has been observed in our laboratory that Ac-Phe-ArgOMe is a much better substrate for porcine pancreatic (Fiedler 1976), submandibular and urinary kallikreins (Fritz et al. 1977) than $\alpha-$ $\mathrm{N}$-acetylated arginine esters. The corresponding ethyl ester, AcPhe-ArgOEt, is the most rapidly hydrolyzed substrate for human urinary kallikrein described as yet (Fiedler et al. 1978). Therefore, a highly sensitive assay for human urinary kallikrein could be developed employing Ac-Phe-ArgOEt as substrate. The assay (Table 4) is analogous to that with Bz-ArgOEt aeveloped by Trauschold and Werle (1961). The reaction sequence is shown in Fig. 2. The sensitivities of this and other assays for human urinary kallikrein are complled in Table 5. The sensitivity of the assay allows the convenient measurement of the esterase activity of human urine. Urine samples $2020-100 \mu 1$ cause a linear absorbance increase of 0.04 to 0.2 per $10 \mathrm{~min}$. Known amounts of human urinary kallikrein added to urine samples raised the esterase activity to the expected extent. If the urine samples contain ethanol it has to be removed by dialysis. Therefore, ethanol intake should be avoided during the urine collection period.

Table 4 .

Assay of human urinary kallikrein using the substrate Ac-Phe-ArgOEt

$2.00 \mathrm{ml} 0.15 \mathrm{M}$ sodium diphosphate buffer, $\mathrm{pH} 8.7$ containing $0.15 \mathrm{M}$ semicarbazidium chloride and $0.0375 \mathrm{M}$ glycine

$0.10 \mathrm{ml} 0.03 \mathrm{M} \mathrm{NAD}$

$0.10 \mathrm{~m} 10.015 \mathrm{M}$ AcPheArgOEt acetate

$0.02 \mathrm{ml}$ alcohol dehydrogenase (100 mg/3.4 m1)

$(0.28+\mathrm{x}) \mathrm{m} 1$ water

5 min preincubation at $25^{\circ} \mathrm{C}$

$(0.5-\mathrm{x}) \mathrm{m} 1$ enzyme solution

Final volume: $3 \mathrm{~m} 1$

The change in absorbance is monitored for $10 \mathrm{~min}$. at $366 \mathrm{~nm}$. 


$$
\begin{aligned}
& \text { AC-Phe-ArgOEt } \stackrel{\text { Kalli IKREIN }}{\longrightarrow} \text { AC-Phe-Arg }+\mathrm{C}_{2} \mathrm{H}_{5} \mathrm{OH} \\
& \mathrm{C}_{2} \mathrm{H}_{5} \mathrm{OH}+\mathrm{NAD} \underset{(\longleftarrow)}{\stackrel{\text { ALKOHOLDEHYDROGENASE }}{\longrightarrow}} \mathrm{CH}_{3}-\mathrm{C} \underset{\mathrm{H}}{=0}+\mathrm{NADH}_{2}
\end{aligned}
$$

Fig. 2. Reaction scheme of kallikrein assay using Ac-Phe-ArgOEt as substrate.

A number of experiments were undertaken to verify that the esterase activity reflects the kallikrein content of urine. Trasylol completely inhibited the esterase activity. Dialysed urine samples of 10 different persons were assayed. The results were compared with those obtained by the dog blood pressure assay, by a radioimmunoassay for human urinary kallikrein (Mann and Geiger 1977) and by the assay with D-Val-Leu-ArgNHNp as substrate (Fig. 3). Though the correlation coefficient of the results of the Ac-Phe-ArgOEt assay and the dog blood pressure assay (Fig. 3a)

Table 5. Absorbance changes in assays of human urinary kallikrein with various substrates.

\begin{tabular}{|c|c|c|c|}
\hline & $\begin{array}{c}\text { BLANK } \\
\left(\Delta A \cdot 10^{3} \times \mathrm{MIN}^{-1}\right)\end{array}$ & $\left(\triangle A \cdot 10^{3} \times M^{-1}{ }^{-1} \times U^{-1}\right)$ & $\begin{array}{l}\text { RELATIVE } \\
\text { SENSITIVITIES }\end{array}$ \\
\hline$A C-P_{H E}-A_{R g} O E t$ & 0.6 & 1100 & 46 \\
\hline D-VaL-Leu-ArgOEt & 0.6 & 430 & 20 \\
\hline $\mathrm{B}_{\mathrm{Z}}$-ARGOET & 0.5 & 24 & 1 \\
\hline Z-TYRONP & 15 & 460 & 19 \\
\hline D-VAL-LEU-ARG-P-NI TRANILI DE & 0.0 & 29 & 1.2 \\
\hline D-Pro-Phe-Arg-P- " " & & 3 & \\
\hline TOS-GLY-PRO-ARG-P- " " & & 1 & \\
\hline$B Z-P_{H E}-V_{A L}-A_{R G}-P-\quad "$ & & 0.3 & \\
\hline GLU-GLY-ARG-P- " " & & 0.3 & \\
\hline
\end{tabular}

(Reaction volume $3 \mathrm{ml}$, cuvette 1 ight path $1 \mathrm{~cm}$ ) 
is rather close to 1 , a considerable scattering of the data is observed. This is not too surprising, since the coefficient of variation of the blood pressure assay for kallikrein amounts to $20 \%$ (Arens and Haberland 1973). The correlation between the Ac-Phe-ArgOEt assay and both the radioimmunoassay (Fig. 3b) and the D-Va1-Leu-Arg-p-nitroanilide assay is even more satisfactory. The excellent correlation between the two enzymatic assays (Fig. 3c) strongly suggests that in both assays the same enzyme is determined. For a mixture of enzymes a similarly good correlation would only be expected if these enzymes were always excreted in identical ratios.

D-Val-Leu-Arg-p-nitroanilide has been suggested quite recently by KABI (Amundsen et al. 1978) as a substrate for the determination
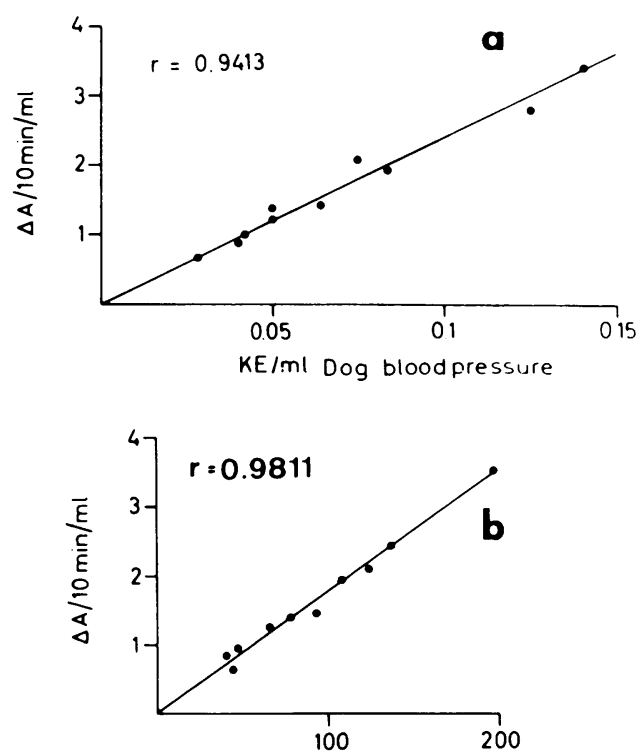

$\mathrm{ng} / \mathrm{ml}$ Kallikrein

RIA

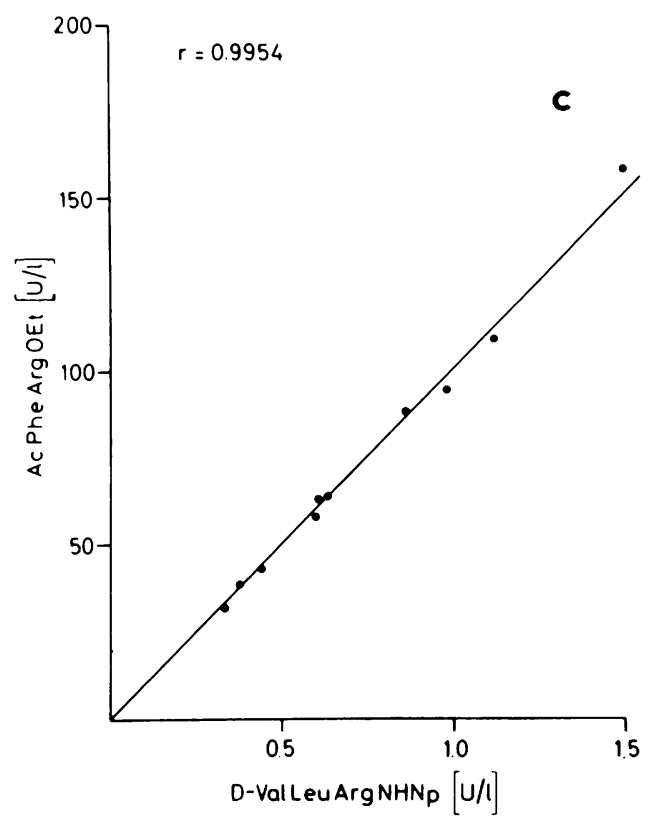

Fig. 3. Comparision of the Ac-Phe-ArgoEt assay for human urinary kallikrein with the blood pressure assay (a), the radioimmunoassay (b) and the D-Val-Leu-ArgNHNp assay (c).

10 samples of human urine were measured. 
of human urinary kallikrein. Hydrolysis of p-nitroanilides can be monitored at $405 \mathrm{~nm}$. Negligible spontaneous hydrolysis of these compounds allows working at $37^{\circ} \mathrm{C}$. To obtain abosrbance changes of sufficient magnitude, an incubation time of 30 min was necessary for urine samples of 50 to $500 \mu 1$. This long incubation time precluded continuous monitoring of the reaction. The results had to be corrected for the inherent absorbance of the urine samples that was determined in parallel (blanks contain water instead of substrate). The reaction conditions are given in Table 6 .

Evident1y, both Ac-Phe-ArgOEt and D-Val-Leu-ArgNHNp are useful substrates for kallikrein determination in human urine. The advantage of the Ac-Phe-ArgOEt assay is the possibility of continuous monitoring during the test, a drawback is the alcohol sensitivity of the reaction. This is not found in the assay with D-Val-Leu-ArgNHNp, but due to its low sensitivity, this method suffers from the disadvantages of a two point assay.

The radioimmunoassay for human urinary kallikrein was also applied to clarify, whether endogenous glandular kallikrein is present in the blood. We found glandular kallikrein in human serum in concentrations of $10-15 \mathrm{ng} / \mathrm{m} 1$. In order to ascertain that the radioimmunoassayable substance was not a low molecular degradation product, serum samples were subjected to gel filtration and the fractions tested by radioimmunoassay (Fig. 4). After gel filtration one peak was detected in the position of a molecular weight of about 80,000 whereas our kallikrein preparation was eluted in the position of about 50,000. The exact origin of the glandular kallikrein in blood is unknown, a discrimination by radioimmunoassay is impossible because of the immunological cross-

Table 6 .

Assay of human urinary kallikrein using the substrate D-Va1-Leu-ArgNHNp

$\begin{array}{rl}\begin{aligned} 0.4 \mathrm{ml} \\ \mathrm{x} \mathrm{m1}\end{aligned} & \begin{array}{l}0.4 \mathrm{M} \text { TRIS } / \mathrm{HC} 1, \mathrm{pH} 8.2 \\ \text { urine } \\ \text { water } \\ (0.5-\mathrm{x}) \mathrm{m} 1\end{array} \\ & 5 \mathrm{~min} \text { preincubation at } 37^{\circ} \mathrm{C} \\ 0.1 \mathrm{ml} & 0.001 \mathrm{M} \mathrm{D-Val-Leu-ArgNHNp} \\ & \text { Incubation at } 37^{\circ} \mathrm{C}\end{array}$

The absorbance increase (405 nm) after $30 \mathrm{~min}$. is read. 
reactivity of the various tissue kallikreins. The presence of glandular kallikrein in blood leads to the assumption that renal filtration might contribute to some extent to the amount of kallikrein found in urine.

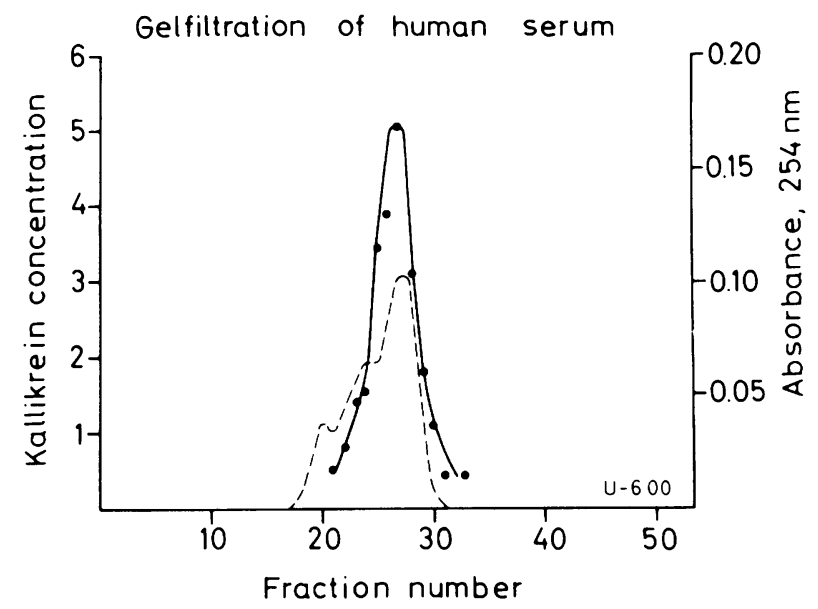

Fig. 4. Gel filtration of human serum through Sephacryl S-200.

The fractions were assayed by a radioimmunoassay for human urinary kallikrein.

\section{ABBREVIATIONS}

Bz-ArgOEt: $\mathrm{N}^{\alpha}$-Benzoyl-arginine ethyl ester, Z-TyrONp: Carbobenzoxytyrosine nitropheny1 ester, Ac-Phe-ArgOMe: Acetyl-phenylalany1arginine methyl ester, Ac-Phe-ArgOEt: Acetyl-phenylalanyl-arginine ethyl ester, Z-Ser-Pro-Phe-Arg-MNA: Carbobenzoxy-sery1-prolylphenylalanyl-arginine-p-nitroanilide, D-Val-Leu-ArgOEt: D-valylleucyl-arginine ethyl ester.

\section{ACKNOWLEDGEMENT}

This work was supported by Deutsche Forschungsgemeinschaft, Sonderforschungsbereich 51, Munchen. We are indebted to Dr. C. Kutzbach, Bayer AG, for providing preprocessed starting material for the isolation of human urinary kallikrein. We thank very much Prof. H. Fritz for his interest in this work and his stimulating discussions and comments. 


\section{REFERENCES}

Amundsen, E., J. Püttner, P. Friberger, M. Knơs, M. Larsbråten, and G. Claeson (1978). Methods for the Determination of Glandular Kallikreins by Means of a Chromogenic Tripeptide Substrate. In press.

Arens, A., and G.L. Haberland (1973). Determination of Kallikrein Activity in Animal Tissue Using Biochemical Methods. In: G.L. Haberland, and J.W. Rohen (Eds.) Kininogenases - Kallikrein 1, F.K. Schattauer Verlag, Stuttgart, pp. 43-53.

Fiedler, F., C. Hirschauer, and E. Werle (1975). Characterization of pancreatic kallikreins A and B. Hoppe Seylers Z. Physiol. Chem. 356, 1879-1891.

Fiedler, R. (1976). Pig Pancreatic Kallikrein: Structure and Catalytic Properties. In: J.J. Pisano and K.F. Austen (Eds.) Chemistry and Biology of the Kallikrein-Kinin System in Health and Disease, DHEW Pub1. No. (NIH) 76-791, pp. 93-95.

Fiedler, F., W. Ehret, G. Godec, C. Hirschauer, C. Kutzbach, G. Schmidt-Kastner, and H. Tschesche (1977). The Primary Structure of Pig Pancreatic Kallikrein B. In: G.L. Haberland, J.W. Rohen, and T. Suzuki (Eds.) Kininogenases - Kallikrein 4, F.K. Schattauer Verlag, Stuttgart, pp. 7-14.

Fiedler, F., R. Geiger, C. Hirschauer, and G. Leysath (1978). Peptide esters and nitroanilides as substrates for the assay of human urinary kallikrein. Hoppe Seylers Z. Physiol. Chem., in press.

Fritz, H., F. Fiedler, T. Diet1, M. Warwas, E. Truscheit, H.J. Kolb, G. Mair, and H. Tschesche (1977). On the Relationship between Porcine Pancreatic, Submandibular, and Urinary Kallikreins. In: G.L. Haberland, J.W. Rohen, and T. Suzuki (Eds.) Kininogenases - Kallikrein 4, F.K. Schattauer Verlag, Stuttgart, pp. 15-28.

Geiger, R., K. Mann, and T. Bettels (1977). Isolation of Human Urinary Kallikrein by Affinity Chromatography. J. C1in. Chem. Clin. Biochem. 15, 479-483.

Hirs, C.H.W. (1976). Methods Enzymo1. 11, 197-199.

Krystal, G., and A.F. Graham (1976). A sensitive method for estimating the carbohydrate content of glycoproteins. Ana1. Biochem. 70, 336-345.

Mann, K., and R. Geiger (1977). Radioimmunoassay of Human Urinary Kallikrein. In: G.L. Haberland, J.W. Rohen, and T. Suzuki (Eds.) Kininogenases - Kallikrein 4, F.K. Schattauer Verlag, Stuttgart, pp. 55-61.

Matsuda, Y., K. Miyazaki, H. Moriya, Y. Fujimoto, Y. Hojima, and C. Moriwaki (1976). Studies on Urinary Kallikrein, I. Purification and Characterization of Human Urinary Kallikrein. J. Biochem. 80, 671-679.

Pisano, J.J., and K.F. Austen (1976). Chemistry and Biology of the Kallikrein-Kinin-System in Health and Disease. DHEW Publication No. (NIH) 76-791. 